\title{
Avaliação da Produção e de Algumas Características da Rebrota de Cultivares e Acessos de Panicum maximum Jacq. sob duas Alturas de Corte ${ }^{1}$
}

\section{Ulysses Cecato ${ }^{3}$, Andréa Oliveira Machado², Elias Nunes Martins ${ }^{3}$, Luiz Alberto Fontes Pereira ${ }^{2}$, Marco Aurélio Alves de Freitas Barbosa ${ }^{2}$, Geraldo Tadeu dos Santos ${ }^{3}$}

\begin{abstract}
RESUMO - O experimento foi realizado no período de setembro de 1995 a setembro de 1996, objetivando avaliar a produção de matéria seca total/ha (PMST), folhas/ha (PMSf), vigor da rebrota (VR), número de perfilhos (NP) e porcentagem de meristemas apicais eliminados (MAE) em seis cultivares de gramíneas (Aruana, Centenário, Colonião, Mombaça, Tanzânia e Tobiatã) e dois acessos (K249 e KK8) de Panicum maximum Jacq., em duas alturas de corte (20 e $40 \mathrm{~cm})$, no período seco e chuvoso. O delineamento experimental foi o de blocos casualizados com parcelas subdivididas. A altura de corte influenciou apenas a PMST e PMSf do capim-tanzânia, que foi maior nos cortes mais baixos no período chuvoso. Os capins Centenário e KK8 apresentaram maiores MAE à altura de $20 \mathrm{~cm}$ e o capim-Aruana, a $40 \mathrm{~cm}$, nos dois períodos. A menor VR foi apresentada pelo capim-Aruana nas duas alturas, nos dois períodos experimentais. Os capins Centenário, KK8, Mombaça, Tanzânia e Tobiatã mostraram maior produção de matéria seca total e de folhas nos dois períodos avaliados, nas duas alturas de corte. Em função dos resultados obtidos, os capins podem ser manejados em qualquer altura de corte, exceto o capim-tanzânia, que pode ser manejado mais baixo.
\end{abstract}

Palavras-chave: matéria seca, matéria seca de folhas, meristemas apicais, perfilhamento, vigor da rebrota

\section{Evaluation of Production and Any Physiological Characteristics of Genotypes of Panicum maximum Jacq. under two Cutting Heights}

\begin{abstract}
The experiment was carried out from September 1995 to September 1996, to evaluate the total dry matter/ha (TDM), of leaves/ha (LDM), regrowth vigor (RV), tillers number (TN), and percentage of eliminated apical meristems (AME) in six grass cultivars (Aruana, Centenario, Colonião, Mombaça, Tanzania and Tobiatã) and two genotypes (K249 and KK8) of Panicum maximum Jacq., at two cutting heights (20 and $40 \mathrm{~cm}$ ), during dry and rainy season. A split plot experimental design was used. The height cutting only influenced the yield of TDM and LDM of Tanzania grass that was higher in lower cuttings during rainy period. The Centenario and KK8 grasses presented higher AME at $20 \mathrm{~cm}$ height and Aruana at $40 \mathrm{~cm}$, in both periods. The lowest RV was to Aruana grass in the two cutting heights in the two experimental periods. The Centenario, KK8, Mombaça, Tanzania e Tobiatã grasses presented higher TDM and LDM both two periods, in the two cutting heights. By the results, the grasses can be managed in any cutting height, except the Tanzania grass, which can be management with low height.
\end{abstract}

Key Words: dry matter, dry matter of leaves, apical meristems, tillering, regrowth vigor

\section{Introdução}

O genêro Panicum maximum Jacq. é originário da África. No Brasil, este cultivar, em geral, apresenta boa produtividade e elevado valor nutritivo, porém práticas inadequadas de manejo e perda da fertilidade dos solos fizeram com que concorresse para a degradação destas pastagens (SOUZA et al., 1996).

Em virtude de estarem sendo lançados novos cultivares que possuem diferenças genéticas e morfofisiológicas e na região Noroeste do Paraná, a atividade pecuária ser intensa, existe a necessidade de novas informações relacionadas à melhor utilização destas gramíneas sob diferentes condições de manejo.

A produção de matéria seca total (MST), perfilhos e emissão de folhas também varia de acordo com a espécie e/ou cultivar. Espécies ou cultivares com alta velocidade de surgimento de folhas possuem numerosos perfilhos (LEMAIRE, 1991). Além disso, qualquer efeito sobre a taxa de alongamento foliar afetará a velocidade de emissão folhas, bem como o surgimento de perfilhos, e conseqüente produção de MST. Entre estes fatores, está a altura de corte. Para plantas de crescimento em touceira, cortes rentes ao solo podem eliminar grande parte da área foliar, além de destruir número elevado de meristemas apicais, o

\footnotetext{
1 Parte da Dissertação do segundo autor.

2 Acadêmico do curso de Mestrado em Zootecnia - UEM.

3 Professor do Departamento de Zootecnia da UEM - Campus Universitário - Av. Colombo, 5790, CEP 87020-900, Maringá - PR.
} 
que implicará em menor rebrota e produção das mesmas (PAULA, et al. 1967). GOMIDE e ZAGO (1980) relataram que plantas de capim Colonião cortadas aos 35 dias, à altura de $15 \mathrm{~cm}$, tiveram $50 \%$ dos seus meristemas apicais eliminados, no entanto, BARBOSA et al. (1996) não obtiveram efeito da altura de corte sobre a eliminação de meristemas apicais, ao avaliarem os capins Colonião, Mombaça, Tanzânia e Tobiatã.

A preservação dos meristemas tem grande importância sobre o vigor da rebrota. Preservando-se os meristemas apicais, haverá formação das folhas novas mais rapidamente e, por conseguinte, a rebrota destas plantas será acelerada (CECATO,1993). Trabalhos de revisão realizados por RODRIGUES e REIS (1995) e SOUZA et al. (1996) mostram que o vigor da rebrota do gênero Panicum está associado, além do índice de área foliar residual, à preservação dos meristemas apicais. GOMIDE (1980) observou que, para esta espécie, a altura de corte de $20 \mathrm{~cm}$ eliminou a maioria dos meristemas apicais, porém FAVORETTO et al. (1987) não constataram influência das alturas de corte de 15 e $30 \mathrm{~cm}$ sobre o vigor da rebrota do capim Colonião.

A eliminação dos meristemas apicais pode influenciar, além do vigor da rebrota, o perfilhamento das plantas (LEMAIRE, 1991).

DRUDI e FAVORETTO (1987) encontraram no capim Andropogon maior densidade de perfilhos à menor altura (10-20 cm), quando comparados à maior altura $(30 \mathrm{~cm})$. Além disso, existe grande variação da produção de matéria seca total e de folhas (MSf) entre os cultivares e espécies, que podem variar em função da época de crescimento, entre outros fatores. Em regiões tropicais, as condições de temperatura e umidade são inadequadas para o bom desenvolvimento das plantas no período seco, porém o contrário ocorre no período chuvoso. JANK (1994) verificou variações na produção de MS total e de folhas do capim Colonião, quando comparou os períodos seco e chuvoso.

A produtividade das plantas forrageiras também pode ser afetada pela área foliar remanescente (MONTEIRO e MORAES, 1996). O manejo por meio da altura de corte é de grande importância na produção de MS; utilizando-se cortes mais baixos, espera-se maiores rendimentos de MS. CECATO et al. (1985), estudando o capim Setária (Setaria anceps Stapf. cv. Kazungula), encontraram maiores rendimentos nas menores alturas, no entanto, FAVORETTO et al. (1987), ao avaliarem o capim
Colonião, não observaram efeito das alturas de corte $(15$ e $30 \mathrm{~cm})$ sobre a produção de MS.

Em função da necessidade de estudos para melhor avaliar os aspectos de manejo, a fim de selecionar cultivares de Panicum maximum Jacq. que se adaptem à região e visando à maior produção, o presente trabalho teve como objetivo avaliar a produção total e de folhas, características da rebrota, perfilhamento e eliminação de meristemas apicais de seis cultivares e dois acessos de Panicum maximum Jacq. sob duas alturas de corte.

\section{Material e Métodos}

O presente trabalho foi conduzido no Setor de Forragicultura da Universidade Estadual de Maringá (UEM), no período de setembro de 1995 a setembro de 1996 . O local situa-se a $23^{\circ} 25^{\prime}$ de latitude Sul, $51^{\circ} 55^{\prime}$ de longitude Oeste, e 554,9 m de altitude. O clima, segundo CORRÊA (1996), é classificado como subtropical úmido mesotérmico com verões quentes, geadas pouco freqüentes e tendência de concentração das chuvas nos meses do verão (Cfa).

O solo do local é classificado como podzólico vermelho escuro, distrófico, de textura média (SEAB, 1985). Antes de iniciar o experimento, foram retiradas amostras de solo e enviadas ao Laboratório de Solos da UEM, para análises químicas, obtendo-se os seguintes resultados: $\mathrm{Al}^{+3}=0,0^{*} ; \mathrm{H}^{+}+\mathrm{Al}^{+3}=2,54^{*}$; $\mathrm{Ca}^{+2}+\mathrm{Mg}^{+2}=2,52 * ; \mathrm{Ca}^{+2}=1,72 * ; \mathrm{K}^{+}=0,22 *, \mathrm{pH}$ $\mathrm{CaCl}_{2}=5,8, \mathrm{P}$ resina $=5,0 \mathrm{ppm}$, teor de $\mathrm{MO}=1,02 \%$, capacidade de troca de cátions $=5,28 *$ e saturação por bases $=51,89 \%(*$ meq $/ 100 \mathrm{~mL}$ terra fina seca ao ar $)$.

Com base nos resultados da análise, foi feita a correção do solo com calcário dolomítico (PRNT de $100 \%$ ), 30 dias antes do início do experimento, procurando-se elevar a saturação por bases a $60 \%$.

$\mathrm{O}$ experimento foi conduzido em área já estabelecida, onde os cultivares e acessos de Panicum maximum Jacq. estavam implantados em parcelas de $4 \mathrm{~m} \times 3 \mathrm{~m}\left(12 \mathrm{~m}^{2}\right)$, em linhas distanciadas de $25 \mathrm{~cm}$. As bordaduras constaram de duas linhas laterais, bem como as extremidades das linhas centrais $(0,5 \mathrm{~m})$.

Após cada corte, foram distribuídos, em cobertura, no período das chuvas, os adubos fosfatado (superfosfato simples), potássico (cloreto de potássio) e nitrogenado (sulfato de amônio), como reposição, com base na produção de matéria seca verde total (PMSVT), respectivamente, 0,$3 ; 2,5$; e $1,5 \%$, de fósforo, potássio e nitrogênio.

Foram considerados dois períodos experimentais: 
662 Rev. bras. zootec.

o período chuvoso - período experimental I (PEI), no qual os cortes foram realizados em 18/12/95, 23/01/ 96, 27/02/96 e 03/04/96, e o período seco - período experimental II (PEII), em que os cortes foram realizados em 12/06/96 e 21/08/96. O corte de uniformização foi realizado em 13/11/95 e os cortes subseqüentes, a cada 35 dias no PEI e 70 dias no PEII.

$\mathrm{O}$ delineamento experimental usado foi o de blocos casualizados, com parcelas subdivididas. Os tratamentos foram seis cultivares de Panicum maximum Jacq. - capim Aruana, capim Centenário, capim Colonião, capim Mombaça, capim Tanzânia, capim Tobiatã - e dois acessos, capim K249 e capim $\mathrm{KK} 8$, nas parcelas principais, e duas alturas de corte $(20$ e $40 \mathrm{~cm})$, nas subparcelas, com três repetições por tratamento, proporcionando 16 combinações dispostas ao acaso, nos blocos.

$\mathrm{O}$ modelo estatístico usado foi:

$$
\begin{aligned}
& \mathrm{y}=\mu \\
& \text { em que }
\end{aligned}
$$

$\mu \quad=$ constante geral;

$\mathrm{B}_{\mathrm{i}} \quad=$ efeito do bloco $i, i=1 ; 2 ; 3$;

$\mathrm{C}_{\mathrm{j}} \quad=$ efeito do cultivar ou acesso $j, j=1 ; 2 ; \ldots ; 8$;

$\mathrm{A}_{\mathrm{k}}=$ efeito da altura $k, k=1 ; 2$; altura $k$;

$\mathrm{CA}_{\mathrm{jk}}=$ produto entre o cultivar ou acesso $j$ e a

$\mathrm{BC}_{\mathrm{ij}}=$ efeito residual das parcelas; e

$\mathrm{e}_{\mathrm{ijk}}=$ erro aleatório associado a cada observação $i j k$.

Para a determinação da produção de matéria seca total (PMST), foi coletado o material vegetativo na área útil de $1 \mathrm{~m}^{2}$, em cada unidade experimental. Após a pesagem do material, foram retiradas amostras representativas de, aproximadamente, $1,5 \mathrm{~kg}$ de cada unidade experimental. Da amostra (30 a 40\%) de massa verde produzida na unidade experimental, foi feita a separação de colmo e folha (altura da lígula). Após pesadas e separadas, as frações foram colocadas em estufa com circulação forçada de ar, a $55^{\circ} \mathrm{C}$, por um período de 72 horas, para determinação da MS parcial.

O número de perfilhos (NP) e de meristemas apicais eliminados (MAE) foi obtido por meio da contagem, do terceiro ao quinto dia após cada corte, em duas touceiras previamente demarcadas na unidade experimental.

Para a determinação do vigor da rebrota (VR), aos 21 dias após o corte, foi coletada a vegetação, de uma área de $0,25 \mathrm{~m}^{2}$, em cada unidade experimental, em áreas adjacentes às utilizadas para avaliação de PMST. Após a coleta, o material foi colocado em estufa a $55^{\circ} \mathrm{C}$, com circulação forçada de ar, por um período de 72 horas, para determinação do peso seco.

A produção de matéria seca de folhas (MSf), por área, foi obtida relacionando-se as produções de MS da fração folha, separadamente, às PMST.

Os dados de precipitação e temperatura, observados durante o período experimental, foram coletados no Posto de Meteorologia da UEM, localizado a, aproximadamente, $500 \mathrm{~m}$ da área do experimento, e encontram-se na Figura 1.

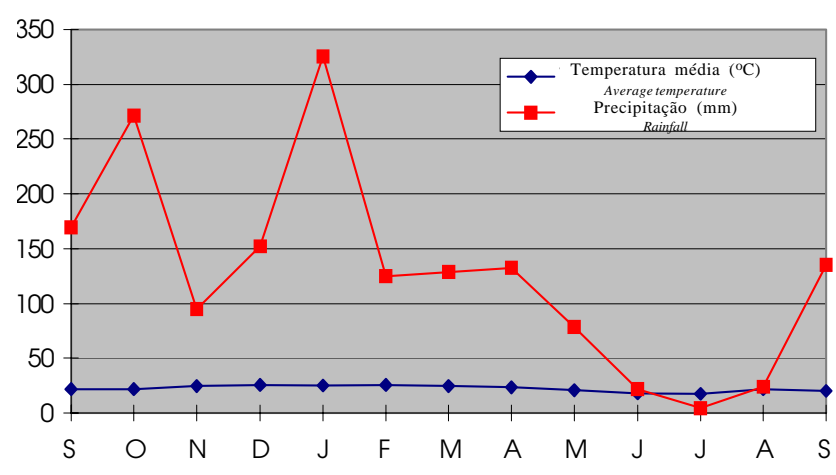

Figura 1 - Precipitação pluviométrica e temperatura média mensal durante o período total do experimento

Figure 1 - Rainfall and average monthly temperature during the experimental period.

\section{Resultados e Discussão}

\section{Período experimental I}

Os resultados da PMST e MSf encontram-se na Tabela 1. Como pode ser observado, à altura de 20 $\mathrm{cm}$, o capim Mombaça produziu mais $(\mathrm{P}<0,05) \mathrm{MST}$ que os capins Aruana e Colonião, todavia apresentou produtividade semelhante aos demais. Comportamento semelhante para o capim Mombaça foi encontrado por CECATO et al. (1996).

A menor produtividade do capim Aruana, em relação à maioria, deve-se, em parte, à morfologia desta planta, pois possui internódios curtos e folhas de pequena dimensão (GHISI et al. 1989).

O capim Mombaça mostrou tendência de produzir 10,75 e $23,11 \%$ mais MST que os capins Tobiatã e Centenário na altura de $20 \mathrm{~cm}$, respectivamente, destacando-se como os mais produtivos, neste período. Outros trabalhos (EUCLIDES et al. 1995 e CECATO et al. 1996) também revelaram comportamento similar. 
$\mathrm{Na}$ altura de corte de $40 \mathrm{~cm}$, o capim Mombaça revelou produção superior $(\mathrm{P}<0,05)$ aos capins Aruana, Colonião, K249e Tanzânia, mas semelhante aos demais.

Estes resultados são consistentes com os citados por SOUZA et al. (1996), que verificaram maior produção de MS dos capins Mombaça e Tanzânia, quando comparados ao capim Colonião. CECATO et al. (1996), avaliando os mesmos cultivares e acessos, verificaram maior PMST somente do capim-KK8 sobre o capim Aruana, e houve semelhança entre os demais. Naquele experimento, o capim Aruana apresentou também comportamento similar ao do capim Colonião.

Os valores médios da PMST mostraram, que, entre alturas de corte, o capim Tanzânia produziu mais $(\mathrm{P}<0,05)$, quando as plantas foram cortadas a 20 $\mathrm{cm}$ do solo. Este fato parece demonstrar que o capim Tanzânia se adapta melhor a cortes mais baixos. A alturas menores, esperam-se, a curto prazo, maiores produções de MST que nas alturas maiores, devido à maior retirada da fração colmo. Porém, FAVORETTO et al. (1987), não encontraram efeito da altura de corte sobre a produção de MS, quando estudaram o capim Colonião. Entretanto, para o capim Andropogon, cortes realizados mais baixos (10 e 20 $\mathrm{cm})$ proporcionaram maiores produções que os mais altos $(30 \mathrm{~cm})$ (DRUDI e FAVORETTO, 1987).

$\mathrm{Na}$ altura de $20 \mathrm{~cm}$, o capim Mombaça apresentou maior $(\mathrm{P}<0,05)$ produção de MSf que os capins KK8, Aruana e Colonião, porém foi semelhante $(\mathrm{P}>0,05)$ aos demais. As produções dos capins Aruana e Colonião estão associadas a sua baixa PMST. A PMSf do capim Aruana representou apenas $62 \% \mathrm{em}$ relação à PMST, muito menos que os demais gramíneas estudadas, porém para o capim Colonião esta representou $78 \%$. A produção de MSf é muito importante do ponto de vista nutricional, pois as folhas das plantas forrageiras tropicais apresentam maior valor nutritivo que os colmos (COSTA et al., 1992; CECATO, 1993). Resultados de pesquisa mostram que há diferenciação na PMST e de folhas entre os cultivares do gênero Panicum, principalmente, entre os capins Mombaça e Tanzânia (JANK e SAVIDAN, 1986; CECATO et al. 1996).

As gramíneas Aruana e Colonião, quando cortadas a $40 \mathrm{~cm}$ do solo, apresentaram menor $(\mathrm{P}<0,05)$ produção de MSf, enquanto o capim Mombaça foi superior $(\mathrm{P}<0,05)$, exceto em relação aos capins Centenário, Tobiatã e KK8. Estes resultados vêm confirmar que fatores genéticos são importantes, quando se avaliam plantas forrageiras, pois apresentam, certamente, características similares ou muito próximas, dificultando a obtenção de resultados mais significativos, independente da altura de corte. Em geral, verificou-se elevada produção de MSf nos capins avaliados, exceto para o capim Aruana.

Com relação à produção de MSf, nas duas alturas de corte, pode-se verificar que somente o capim Tanzânia foi mais produtivo $(\mathrm{P}<0,05)$, quando cortado a $20 \mathrm{~cm}$ de altura. Este fato confirma as observações de FAVORETTO et al. (1987), os quais relataram

Tabela 1 - Produções de matéria seca verde total (PMSVT) e de folhas (PMSVF) dos cultivares e acessos do gênero Panicum, em função das alturas de corte $(20$ e $40 \mathrm{~cm})$ no PEI

Table 1 - Total dry matter (TDM) and leaves dry matter (LDM) genotypes of Panicum in function of the cutting heights $(20$ and $40 \mathrm{~cm})$ in PEI

\begin{tabular}{|c|c|c|c|c|}
\hline \multirow[t]{3}{*}{$\begin{array}{l}\text { Altura }(\mathrm{cm}) \\
\text { Height }(\mathrm{cm})\end{array}$} & \multicolumn{4}{|c|}{$\begin{array}{l}\text { Cultivar } \\
\text { Genotype }\end{array}$} \\
\hline & 20 & 40 & 20 & 40 \\
\hline & \multicolumn{2}{|c|}{$\begin{array}{c}\text { PMSVT }(\mathrm{kg} / \mathrm{ha}) \\
T D M\end{array}$} & \multicolumn{2}{|c|}{$\begin{array}{c}\text { PMSVF }(\mathrm{kg} / \mathrm{ha}) \\
L D M\end{array}$} \\
\hline Aruana & $5.996^{\mathrm{Ca}^{*}}$ & $6.079^{\mathrm{Da}}$ & $3.743^{\mathrm{Ca}}$ & $3.889^{\mathrm{Ea}}$ \\
\hline Centenário & $17.177^{\mathrm{Aa}}$ & $18.191^{\mathrm{Aa}}$ & $13.439 \mathrm{ABa}$ & $15.186^{\mathrm{ABa}}$ \\
\hline Colonião & $11.039 \mathrm{~B} C a$ & $10.675^{\mathrm{Ca}}$ & $8.716^{\mathrm{BCa}}$ & $9.280^{\mathrm{Da}}$ \\
\hline KK8 & $16.680^{\mathrm{Aa}}$ & $17.307^{\mathrm{ABa}}$ & $12.980^{\mathrm{Ba}}$ & $13.999 \mathrm{ABCa}$ \\
\hline $\mathrm{K} 249$ & $16.171 \mathrm{~A}^{\mathrm{Ba}}$ & $13.983^{\mathrm{BCa}}$ & $12.649^{\mathrm{ABa}}$ & $11.854^{\mathrm{BCDa}}$ \\
\hline Mombaça & $21.146^{\mathrm{Aa}}$ & $19.872^{\mathrm{Aa}}$ & $16.524^{\mathrm{Aa}}$ & $16.940^{\mathrm{Aa}}$ \\
\hline Tanzânia & $16.566^{\mathrm{Aa}}$ & $12.273^{\mathrm{Cb}}$ & $13.551^{\mathrm{ABa}}$ & $11.028^{\mathrm{CDb}}$ \\
\hline Tobiatã & $19.093^{\mathrm{Aa}}$ & $16.826^{\mathrm{ABa}}$ & $15.002^{\mathrm{Aa}}$ & $14.006^{\mathrm{ABCa}}$ \\
\hline $\mathrm{CV}(\%)$ & \multicolumn{2}{|c|}{11,04} & \multicolumn{2}{|c|}{12,34} \\
\hline
\end{tabular}


664 Rev. bras. zootec.

que, mesmo sendo cortado ou pastejado mais próximo do solo, sua produtividade parece não ser afetada. Os resultados acompanham, em parte, os registros de literatura (CECATO et al., 1996; DRUDI e FAVORETTO, 1987; e VIANA et al., 1993), na qual se constata que a forrageira colhida em níveis mais elevados do solo apresenta maior quantidade de MSf.

Os valores médios do vigor da rebrota (VR), dos meristemas apicais eliminados por touceira (MAE) e dos perfilhos vivos por touceira (NP) são apresentados na Tabela 2. O capim Aruana, quando cortado a $20 \mathrm{~cm}$, apresentou o menor $(\mathrm{P}<0,05) \mathrm{VR}$, mas foi semelhante somente aos capins Centenário e KK8. Este fato se deve às características de crescimento, à morfologia e aos seus meristemas apicais, que se elevaram mais rapidamente que os outros cultivares, conforme relatado por GHISI et al. (1989) e ALCÂNTARA et al. (1991). Uma vez que o VR pode estar relacionado à eliminação dos meristemas apicais, este fato contribui para o menor vigor da rebrota.

O corte a $40 \mathrm{~cm}$ de altura proporcionou VR do capim Mombaça superior $(\mathrm{P}<0,05)$ apenas aos dos capins Aruana e K249, mas semelhante aos demais. Este comportamento pode estar associado à semelhança ocorrida da eliminação do meristema apical (Tabela 2).

Houve efeito entre alturas $(\mathrm{P}<0,05)$ apenas para os capins Mombaça e KK8, sendo o VR maior a 40 $\mathrm{cm}$. O capim KK8 apresentou o menor VR, provavelmente, porque pode estar associado ao maior número de meristemas apicais eliminados à altura de $20 \mathrm{~cm}$. Embora não tenha sido observado o efeito da altura de corte, para o capim Mombaça, a eliminação dos meristemas apicais também foi maior à altura de $20 \mathrm{~cm}$. Para plantas de crescimento em touceira, cortes próximos ao solo podem eliminar grande parte da área foliar, além de destruir número elevado de meristemas apicais, o que implicará em menor rebrota e produção das mesmas (LANGER, 1972; DRUDI e FAVORETTO, 1987). Em geral, ao se relacionar o VR com a PMST (Tabela 1 e 2), verifica-se que não houve influência sobre a PMST dos capins avaliados.

$\mathrm{Na}$ altura de corte de $20 \mathrm{~cm}$, os capins Aruana e KK8 tiveram mais meristemas eliminados $(\mathrm{P}<0,05)$ que os capins Colonião e Tobiatã.

A eliminação de meristemas apicais pelo corte a $40 \mathrm{~cm}$ foi maior $(\mathrm{P}<0,05)$ no capim Aruana, em decorrência de maior precocidade e alongamento intenso de seus colmos; resultados que estão de acordo com os relatados por SOUZA et al. (1996).

$\mathrm{O}$ número de perfilhos, à altura de $20 \mathrm{~cm}$, não revelou diferença $(\mathrm{P}>0,05)$ entre os cultivares $\mathrm{e}$ acessos avaliados. Também na altura de $40 \mathrm{~cm}$, a densidade de perfilhos foi semelhante, exceto para o capim Aruana, que foi maior $(\mathrm{P}<0,05)$ em relação aos demais. Os capins Centenário e KK8 tiveram maior perfilhamento no nível mais baixo $(20 \mathrm{~cm})$. Isso pode ser explicado pela relação entre o número de perfilhos

Tabela 2 - Vigor da rebrota (VR), número de meristemas apicais eliminados por touceira (MAE) e número perfilhos (NP) por touceira dos cultivares e acessos do gênero Panicum, em função das alturas de corte $(20$ e $40 \mathrm{~cm})$ no PEI

Table 2 - Regrowth vigor (RV), number of eliminated apical meristems (AME) and tillers number (TN) genotypes of Panicum, in function of the cutting heights $(20$ and $40 \mathrm{~cm})$ in PEI

\begin{tabular}{|c|c|c|c|c|c|c|}
\hline \multirow{4}{*}{$\begin{array}{l}\text { Cultivar } \\
\text { Genotype }\end{array}$} & \multicolumn{6}{|c|}{$\begin{array}{l}\text { Altura }(\mathrm{cm}) \\
\text { Height }(\mathrm{cm})\end{array}$} \\
\hline & 20 & 40 & 20 & 40 & 20 & 40 \\
\hline & \multicolumn{2}{|c|}{ VR (kg/ha) } & \multicolumn{2}{|c|}{ MAE } & \multicolumn{2}{|c|}{ NP } \\
\hline & \multicolumn{2}{|c|}{$R V$} & \multicolumn{2}{|c|}{$A M E$} & \multicolumn{2}{|c|}{$T N$} \\
\hline Aruana & $3.496^{\mathrm{Ba}^{*}}$ & $4.380^{\mathrm{Ca}}$ & $20^{\mathrm{Aa}}$ & $25^{\mathrm{Aa}}$ & $33^{\mathrm{Aa}}$ & $57^{\mathrm{Ab}}$ \\
\hline Centenário & $5.852^{\mathrm{ABa}}$ & $7.372^{\mathrm{ABCa}}$ & $15^{\mathrm{ABa}}$ & $9^{\mathrm{Bb}}$ & $36^{\mathrm{Aa}}$ & $24^{\mathrm{Bb}}$ \\
\hline Colonião & $7.380^{\mathrm{Aa}}$ & $8.000^{\mathrm{ABCa}}$ & $9^{\mathrm{Ba}}$ & $9^{\mathrm{Ba}}$ & $20^{\mathrm{Aa}}$ & $23^{\mathrm{Ba}}$ \\
\hline KK8 & $5.748^{\mathrm{ABa}}$ & $8.600^{\mathrm{ABCb}}$ & $20^{\mathrm{Aa}}$ & $11^{\mathrm{Bb}}$ & $33^{\mathrm{Aa}}$ & $21^{\mathrm{Bb}}$ \\
\hline K249 & $7.152^{\mathrm{Aa}}$ & $7.008^{\mathrm{BCa}}$ & $10^{\mathrm{ABa}}$ & $8^{\mathrm{Ba}}$ & $25^{\mathrm{Aa}}$ & $25^{\mathrm{Ba}}$ \\
\hline Mombaça & $7.164^{\mathrm{Aa}}$ & $10.992^{\mathrm{Ab}}$ & $12^{\mathrm{ABa}}$ & $9^{\mathrm{Ba}}$ & $28^{\mathrm{Aa}}$ & $25^{\mathrm{Ba}}$ \\
\hline Tanzânia & $7.308^{\mathrm{Aa}}$ & $9.124^{\mathrm{ABa}}$ & $11^{\mathrm{ABa}}$ & $11^{\mathrm{Ba}}$ & $31^{\mathrm{Aa}}$ & $27^{\mathrm{Ba}}$ \\
\hline Tobiatã & $6.460^{\mathrm{Aa}}$ & $7.636^{\mathrm{ABCa}}$ & $7^{\mathrm{Ba}}$ & $7^{\mathrm{Ba}}$ & $17^{\mathrm{Aa}}$ & $22^{\mathrm{Ba}}$ \\
\hline $\mathrm{CV}(\%)$ & \multicolumn{2}{|c|}{16,96} & \multicolumn{2}{|c|}{23,37} & \multicolumn{2}{|c|}{26,04} \\
\hline
\end{tabular}

* Médias seguidas de letras distintas (maiúsculas nas colunas e minúsculas nas linhas) diferem pelo teste Tukey (P<0,05).

${ }^{*}$ Means, followed by different letters (capital in the columns and small in the row) are different by Tukey test $(P<.05)$. 
e a quantidade de meristemas apicais no capim Aruana, que apresentou número maior de meristemas apicais a $40 \mathrm{~cm}$, enquanto, para as outras duas gramíneas, a redução no perfilhamento coincidiu com o menor número de meristemas apicais, concordando com os resultados GOMIDE et al. (1979) e DRUDI e FAVORETTO (1987).

$O$ perfilhamento foi semelhante $(\mathrm{P}>0,05)$ entre os demais cultivares e acessos avaliados. No entanto, COSTA et al. (1992) encontraram maior número de perfilhos para capim Colonião, quando comparado ao capim Tobiatã, e HERLING et al. (1995) verificaram que o capim Colonião perfilhou mais que o capim Centenário.

\section{Período experimental II}

Neste período, à altura de corte de $20 \mathrm{~cm}$, o capim Mombaça foi mais produtivo $(\mathrm{P}<0,05)$ que os capins Aruana, Colonião e K249 e semelhante aos demais (Tabela 3), no entanto, CECATO et al. (1996), avaliando estes cultivares e acessos, encontraram menores PMST somente para o capim Aruana. $\mathrm{Na}$ altura de corte de $40 \mathrm{~cm}$, o capim Mombaça foi superior $(\mathrm{P}<0,05)$ aos capins Aruana, Colonião, K249 e Tobiatã. Resultados semelhantes foram encontrados por EUCLIDES et al. (1995) e JANK (1994).

A menor produtividade apresentada pelo capim Aruana pode ser explicada, provavelmente, pela morfologia da planta, pois o mesmo têm internódios e folhas menores que os demais cultivares e acessos avaliados (GHISI et al., 1989).

Os capins Centenário, Mombaça, Tanzânia e Tobiatã apresentaram maior PMST $(\mathrm{P}<0,05)$, quando cortados a $20 \mathrm{~cm}$. Em geral, o corte mais alto possibilita a retirada menor da quantidade de colmos, afetando a PMST, conforme FAVORETTO et al. (1995). Entretanto, FAVORETTO et al. (1987) não encontraram efeito da altura de corte sobre a produção de MS, ao avaliarem o capim Colonião.

Os capins que apresentaram maior PMST no PEI, em geral, também foram mais produtivos no PEII (Tabelas 1 e 3 ). A produtividade do PEII, para os capins KK8, Mombaça, Centenário e Tobiatã representou, em média, 30, 25, 23 e 19\% da PMST do PEI. A PMST para o capim Mombaça foi superior à obtida por JANK (1994).

A produção de MSf à altura de $20 \mathrm{~cm}$ foi maior $(\mathrm{P}<0,05)$ para o capim Mombaça, quando comparado aos capins Aruana, Colonião e K249. A produção de MSf do capim Mombaça correspondeu a $82 \%$ da PMST. Estes resultados são superiores aos encontrados por JANK (1994). Os baixos valores de MSf encontrados para estes três últimas gramíneas podem estar relacionados à sua pequena PMST.

$\mathrm{O}$ capim Mombaça, quando coletado à altura de corte de $40 \mathrm{~cm}$, apresentou maior $(\mathrm{P}<0,05)$ produção de MSf que os demais capins avaliados. Isto pode estar relacionado à PMST, uma vez que a produção de MSf representou 94\% da PMST.

Tabela 3 - Produções de matéria seca verde total (PMSVT) e de folhas (PMSVF) dos cultivares e acessos do gênero Panicum, em função das alturas de corte $(20$ e $40 \mathrm{~cm})$ no PEll

Table 3 - Total dry matter (TDM) and leaves dry matter (LDM) genotypes of Panicum in function of the two cutting height $(20$ and $40 \mathrm{~cm})$ in PEIl

\begin{tabular}{|c|c|c|c|c|}
\hline \multirow[b]{3}{*}{$\begin{array}{l}\text { Cultivar } \\
\text { Genotype }\end{array}$} & \multicolumn{4}{|c|}{$\begin{array}{l}\text { Altura }(\mathrm{cm}) \\
\text { Height }(\mathrm{cm})\end{array}$} \\
\hline & 20 & 40 & 20 & 40 \\
\hline & \multicolumn{2}{|c|}{$\operatorname{PMSVT}(\mathrm{kg} / \mathrm{ha})$} & \multicolumn{2}{|c|}{$\operatorname{PMSVF}(\mathrm{kg} / \mathrm{ha})$} \\
\hline Aruana & $1480^{\mathrm{Ba}^{*}}$ & $721^{\mathrm{Da}}$ & $1140^{\mathrm{Ba}}$ & $635^{\mathrm{Da}}$ \\
\hline Centenário & $5099^{\mathrm{Aa}}$ & $3209^{\mathrm{ABb}}$ & $4487^{\mathrm{Aa}}$ & $3007^{\mathrm{Bb}}$ \\
\hline Colonião & $1326^{\mathrm{Ba}}$ & $1235^{\mathrm{CDa}}$ & $555^{\mathrm{Ba}}$ & $590^{\mathrm{Da}}$ \\
\hline KK8 & $5597^{\mathrm{Aa}}$ & $4749^{\mathrm{Aa}}$ & $3857^{\mathrm{Aa}}$ & $3134^{\mathrm{Ba}}$ \\
\hline K249 & $2443^{\mathrm{Ba}}$ & $2216^{\mathrm{BCDa}}$ & $1575^{\mathrm{Ba}}$ & $1443^{\mathrm{CDa}}$ \\
\hline Mombaça & $5753^{\mathrm{Aa}}$ & $4648^{\mathrm{Ab}}$ & $4763^{\mathrm{Aa}}$ & $4367^{\mathrm{Aa}}$ \\
\hline Tanzânia & $4826^{\mathrm{Aa}}$ & $3722^{\mathrm{ABb}}$ & $3839^{\mathrm{Aa}}$ & $3221^{\mathrm{Ba}}$ \\
\hline Tobiatã & $4646^{\mathrm{Aa}}$ & $2633^{\mathrm{BCb}}$ & $4190^{\mathrm{Aa}}$ & $2515^{\mathrm{BCb}}$ \\
\hline $\mathrm{CV}(\%)$ & \multicolumn{2}{|c|}{17,10} & \multicolumn{2}{|c|}{18,64} \\
\hline
\end{tabular}

* Médias seguidas de letras distintas (maiúsculas nas colunas e minúsculas nas linhas) diferem pelo teste Tukey $(\mathrm{P}<0,05)$.

* Means, followed by different letters (capital in the columns and small in the row) are different by Tukey test $(P<.05)$. 
Os capins Centenário e Tobiatã produziram maior MSf durante o PEII, quando as plantas foram cortadas à altura de $20 \mathrm{~cm}$.

Comparando-se os resultados das Tabelas 2 e 4 observou-se que há menor decapitação de meristemas apicais no PEII, para a maioria dos capins, o que certamente pode ter contribuído para a maior produção de folhas. Além disso, neste período, devido à influência de fatores climáticos, como precipitação e temperatura, há menor desenvolvimento vegetativo da planta, o que proporciona maior quantidade de folhas (LANGER, 1972).

Os capins Colonião e K249 foram os que apresentaram boa produtividade no verão, porém muito baixa no período seco.

O VR (Tabela 4), à altura de $20 \mathrm{~cm}$, foi diferente entre o capins Mombaça e Aruana, mas semelhante aos demais. O VR do capim Mombaça, a $40 \mathrm{~cm}$, foi superior $((\mathrm{P}<0,05)$ aos capins Aruana $\mathrm{e}$ Centenário; o capim Mombaça também produziu mais MSVT (Tabela 3).

Entre alturas de corte, o VR das plantas foi semelhante $(\mathrm{P}>0,05)$ para as gramíneas avaliadas. Relacionando-se o VR com o número de perfilhos (Tabela 4), pode-se observar comportamento similar, constatando-se que o VR neste período não foi influenciado pelo número de perfilhos. A pequena variação para este parâmetro deve-se, em parte, às condições climáticas da época (Figura 1) e à falta de umidade e temperatura adequada, que devem ter paralisado os processos metabólicos das plantas durante o PEII (LANGER, 1972).

$\mathrm{Na}$ altura de $20 \mathrm{~cm}$, o capim KK8 apresentou maior $(\mathrm{P}<0,05)$ número de meristemas apicais eliminados que os capins Aruana, Colonião, Tanzânia e Tobiatã, porém foi semelhante $(\mathrm{P}>0,05)$ aos demais. Entretanto, a $40 \mathrm{~cm}$, o capim KK8 apresentou maior quantidade $(\mathrm{P}<0,05)$ de meristemas apicais eleminados que os capins Aruana, Centenário, Tanzânia e Tobiatã.

Certamente, a maior eliminação de meristemas apicais para o capim KK8 ocorreu em função do maior alongamento do colmo, o que pode ter contribuído, em parte, para a sua PMST, pois foi um dos capins mais produtivos. Cortes mais baixos possibilitaram maior eliminação de meristemas apicais, nos capins Centenário e KK8, o que também foi relatado por PAULA et al. (1967) e GOMIDE e ZAGO (1980).

A densidade de perfilhos foi semelhante $(\mathrm{P}>0,05)$ nos cultivares e acessos avaliados, nas duas alturas e entre alturas de corte. Todavia, a tendência de maior número de perfilhos do capim Aruana pode ser explicado, em parte, pelo fato de que este cultivar pode apresentar alta velocidade de surgimento de folhas, o que promove o maior potencial de perfilhamento deste, pois o perfilhamento é

Tabela 4 - Vigor da rebrota (VR), número de meristemas apicais eliminados por touceira (MAE) e número de perfilhos por touceira (NP) dos cultivares e acessos do gênero Panicum, em função das alturas de corte $(20$ e $40 \mathrm{~cm})$ no PEII

Table 4 - Tillers number (TN), number of the eliminated apical meristems (AME) and regrowth vigor (RV) genotypes of Panicum in function of the cutting heights $(20$ and $40 \mathrm{~cm})$ in PEII

\begin{tabular}{|c|c|c|c|c|c|c|}
\hline \multirow{4}{*}{$\begin{array}{l}\text { Cultivar } \\
\text { Genotype }\end{array}$} & \multicolumn{6}{|c|}{$\begin{array}{l}\text { Altura }(\mathrm{cm}) \\
\text { Height }(\mathrm{cm})\end{array}$} \\
\hline & 20 & 40 & 20 & 40 & 20 & 40 \\
\hline & \multicolumn{2}{|c|}{ VR(kg/ha) } & \multicolumn{2}{|c|}{ MAE } & \multicolumn{2}{|c|}{ NP } \\
\hline & \multicolumn{2}{|c|}{$R V$} & \multicolumn{2}{|c|}{$A M E$} & \multicolumn{2}{|c|}{$T N$} \\
\hline Aruana & $700^{\mathrm{Ba}}$ & $460^{\mathrm{Aa}}$ & $3^{\mathrm{Ba}}$ & $3^{\mathrm{Ba}}$ & $33^{\mathrm{Aa}}$ & $42^{\mathrm{Aa}}$ \\
\hline Centenário & $1.252^{\mathrm{ABa}}$ & $884^{\mathrm{Aa}}$ & $6^{\mathrm{ABa}}$ & $3^{\mathrm{Bb}}$ & $36^{\mathrm{Aa}}$ & $24^{\mathrm{Aa}}$ \\
\hline Colonião & $1.136^{\mathrm{ABa}}$ & $1516^{\mathrm{Aa}}$ & $3^{\mathrm{Ba}}$ & $5^{\mathrm{ABa}}$ & $17^{\mathrm{Aa}}$ & $19^{\mathrm{Aa}}$ \\
\hline KK8 & $1.368^{\mathrm{ABa}}$ & $780^{\mathrm{Aa}}$ & $14^{\mathrm{Aa}}$ & $10^{\mathrm{Ab}}$ & $31^{\mathrm{Aa}}$ & $19^{\mathrm{Aa}}$ \\
\hline K249 & $864^{\mathrm{ABa}}$ & $2176^{\mathrm{Aa}}$ & $6^{\mathrm{ABa}}$ & $4^{\mathrm{ABa}}$ & $20^{\mathrm{Aa}}$ & $19^{\mathrm{Aa}}$ \\
\hline Mombaça & $1.989^{\mathrm{Aa}}$ & $1960^{\mathrm{Aa}}$ & $4^{\mathrm{ABa}}$ & $5^{\mathrm{ABa}}$ & $21^{\mathrm{Aa}}$ & $22^{\mathrm{Aa}}$ \\
\hline Tanzânia & $1.428^{\mathrm{ABa}}$ & $1136^{\mathrm{Aa}}$ & $3^{\mathrm{Ba}}$ & $2^{\mathrm{Ba}}$ & $25^{\mathrm{Aa}}$ & $24^{\mathrm{Aa}}$ \\
\hline Tobiatã & $1.616^{\mathrm{ABa}}$ & $1724^{\mathrm{Aa}}$ & $3^{\mathrm{Ba}}$ & $1^{\mathrm{Ba}}$ & $21^{\mathrm{Aa}}$ & $21^{\mathrm{Aa}}$ \\
\hline $\mathrm{CV}(\%)$ & \multicolumn{2}{|c|}{43,82} & \multicolumn{2}{|c|}{36,34} & \multicolumn{2}{|c|}{62,30} \\
\hline
\end{tabular}

* Médias seguidas de letras distintas (maiúsculas nas colunas e minúsculas nas linhas) diferem pelo teste Tukey $(\mathrm{P}<0,05)$.

${ }^{*}$ Means, followed by different letters (capital in the columns and small in the row) are different by Tukey test $(P<.05)$. 
determinado pela velocidade de emissão de folhas (LEMAIRE, 1991), porém isso não refletiu em maior PMST. WARMKE (1951), ao comparar alguns cultivares de Panicum maximum Jacq., observou variação entre 16 e 57 perfilhos por planta.

Comparando-se os PEI e PEII, observa-se que, em geral, o número de perfilhos foi semelhante, o que também foi observado para o capim Aruana por ALCÂNTARA et al. (1991). CECATO (1993), estudando o mesmo capim nos períodos seco e chuvoso, relatou que o número de perfilhos foi maior no segundo. Contudo, MECELIS (1979), para o capimColonião, encontrou redução no perfilhamento do período chuvoso, quando comparado ao seco.

\section{Conclusões}

Os capins Centenário, KK8, Mombaça, Tanzânia e Tobiatã apresentaram maior produção de matéria seca total e de folhas nos dois períodos avaliados, nas duas alturas de corte, independente da eliminação de meristemas apicais e da densidade de perfilhos. Entretanto, a altura de corte não afetou esses parâmetros dos capins avalilados, exceto para o capim Tanzânia, que foi mais produtivo nos cortes mais baixos, no período chuvoso.

A altura de corte não influenciou o vigor da rebrota e a densidade de perfílhos nos capins avaliados, no período de maior crescimento, à exceção dos capins Mombaça e KK8, que apresentaram o menor vigor da rebrota, quando as plantas foram colhidas mais próximas do nível do solo, o que pode estar associado à maior eliminação de meristemas apicais.

Os capins podem ser manejados em qualquer altura de corte, exceto o capim Tanzânia, que pode ser manejado mais baixo.

\section{Referências Bibliográficas}

ALCÂNTARA, V.B.G., ALMEIDA, A.R.P., GHISI, O.M.A. 1991. Estudo fisiológico de seis cultivares de Panicum maximum Jacq. Bol. Ind. Anim., 42(1):47-67.

ANDRADE, J.B. Estudo comparativo de três capins da espécie Panicum maximum Jacq. (Colonião, Tobiatã e K-87B). Piracicaba, SP, ESALQ, 1987. 131p. Dissertação (Mestrado em Zootecnia) - Escola Superior de Agricultura Luiz de Queiroz, 1987.

BARBOSA, M.A.A.F., DAMASCENO, J.C., CECATO, U. et al. Influência da eliminação do meristema apical, em quatro cultivares de Panicum maximum Jacq.. In: REUNIÃO ANUAL DA SOCIEDADE BRASILEIRA DE ZOOTECNIA, 33, 1996, Fortaleza. Anais... Fortaleza: SBZ, 1996. p.104-105.

CECATO, U. Influência da freqüência de corte, níveis e formas de aplicação do nitrogênio sobre a produção, a composição química e algumas características da rebrota do capim Aruana (Panicum maximum Jacq. cv. Aruana). Jaboticabal, SP, UNESP, 1993. 112p. Tese (Doutorado em Produção Animal) - Universidade Estadual Paulista, 1993.

CECATO, U., BARBOSA, M.A.A.F., SAKAGUTI, E.S. et al. Avaliação de cultivares de Panicum maximum Jacq. In: REUNIÃO ANUAL DA SOCIEDADE BRASILEIRA DE ZOOTECNIA, 33, 1996, Fortaleza. Anais... Fortaleza: SBZ, 1996. p.109-111.

CECATO, U., SANTOS, G.L., BARRETO, I.L. 1985. Efeito de doses de nitrogênio e alturas de corte sobre a produção, qualidade e reservas de glicídios de Setaria anceps Stapf. cv. Kazungula. Rev. Cen. Rur., 15(4):367-378.

CORRÊA, A.R. 1996. Forrageiras: aptidão climática do estado do Paraná. In: MONTEIRO, A.L.G., MORAES, A., CORRÊA, E.A.S. et al. (Eds.) Forragicultura no Paraná. Londrina: CPAF, p.75-92.

Costa, C. FAVoretto, V., MALheiros, E.B. 1992. Estudo da variação na estrutura da vegetação de duas cultivares de Panicum maximum Jacq. (Colonião e Tobiatã) submetidas a diferentes tipos de manejo. 1. Produção e densidade de perfilhos e matéria seca. Pesq. Agrop. Bras., 27(1):131-142.

DRUDI, A., FAVORETTO, V. 1987. Influência da freqüência, época e altura de corte na produção e composição química do capim Andropógon. Pesq. Agrop. Bras., 22(11):1287-1292.

EUCLIDES, V.P.B., MACEDO, M.C.M., OLIVEIRA, M.P. Avaliação de ecotipos de Panicum maximum Jacq. sob pastejo em pequenas parcelas. In: REUNIÃO ANUAL DA SOCIEDADE BRASILEIRA DE ZOOTECNIA, 32, 1995, Brasília. Anais... Brasília: SBZ, 1995. p. 97-99.

FAVORETTO, V., CECATO, U., GUIDELI, C. et al. Avaliação da estrutura da vegetação do Capim Colonião em função de práticas de manejo. In: REUNIÃO ANUAL DA SOCIEDADE BRASILEIRA DE ZOOTECNIA, 32, 1995, Brasília. Anais... Brasília: SBZ, 1995. p.45-48.

FAVORETTO, V., TONINI JR., R., REIS, R.A. 1987. Efeito da altura e da freqüência de corte sobre a produção, composição química e vigor da rebrota do capim Colonião. Pesq. Agrop. Bras., 22(11):1279-1285.

GHISI, O.M.A., ALMEIDA, A.R.P., ALCÂNTARA, V.B.D. 1989. Avaliação agronômica de 6 cultivares de Panicum maximum Jacq. sobre 3 níveis de adubação. Bol. Ind. Anim., 46(1):1-15.

GOMIDE, J.A. 1980. Les graminées fourragères: description, fonctionnement, application à la culture de l'herbe. Paris: Bordas. 306p.

GOMIDE, J.A., OBEID, J.A., RODRIGUES, L.R.A. 1979. Fatores morfofisiológicos da rebrota do capim Colonião(Panicum maximum). R. Soc. Bras. Zootec., $8(4): 532-562$

GOMIDE, J.A., ZAGO, C.P. 1980. Crescimento e recuperação do capim Colonião após o corte. R. Soc. Bras. Zootec., 9(2):293-305.

HERLING, V.R., RODRIGUES, J.C.M., NOGUEIRA FILHO, et al. Efeito de níveis de nitrogênio sobre os cultivares Colonião e Centenário (Panicum maximum Jacq.) I. Características fisiológicas. In: REUNIÃO ANUAL DA SOCIEDADE BRASILEIRA DE ZOOTECNIA, 32, 1995, Brasília. Anais... Brasília: SBZ, 1995. p.71-73.

JANK, L. Potencial do gênero Panicum. In: SIMPÓSIO BRASILEIRO DE FORRAGEIRAS E PASTAGENS, 11, 1994, Campinas. Anais... Campinas: CBNA, 1994. p.25-31.

JANK, L., SAVIDAN, Y.H. Avaliação preliminar do germoplasma de Panicum maximum introduzido da África. 
668 Rev. bras. zootec.

Produção de sementes e comportamento do florescimento. In: REUNIÃO ANUAL DA SOCIEDADE BRASILEIRA DE ZOOTECNIA, 23, 1986, Campo Grande. Anais... Campo Grande: SBZ, 1986. p.243.

LANGER, R.H.M. 1972. How grasses grow. London: Edward Arnold Publ. Ltda. 60p.

LEMAIRE, G. 1991. Physiologie des graminées fourragéres: croissance. Tech. Agric., 220(3):18.

MECELIS, N.R. Estudo da rebrota do capim Colonião(Panicum maximum Jacq.) submetido a diferentes tipos de manejo. Jaboticabal, SP, UNESP, 1979. 57p. Dissertação (Mestrado em Zootecnia) - Universidade Estadual Paulista, 1979.

MONTEIRO, A.L.G., MORAES, A. 1996. Fisiologia e morfologia de plantas forrageiras In: MONTEIRO, A.L.G., MORAES, A., CORRÊA, E.A.S. et al. (Eds.) Forragicultura no Paraná. Londrina: CPAF. p.75-92.

PAULA, R.R., GOMIDE, J.A., SYKES, D. 1967. Influência de diferentes sistemas de cortes sobre capim Gordura (Melinis minutiflora Beauv.). Rev. Ceres, 14(80):157-186.

RODRIGUES, L.R. de A., REIS, R.A. Bases para o estabelecimento do manejo de capins do gênero Panicum maximum. In: SIMPÓSIO SOBRE MANEJO DA PASTAGEM, 12, 1995, Piracicaba. Anais... Piracicaba: FEALQ, 1995. p. 197-218.
SECRETARIA DE AGRICULTURA DO ESTADO DO PARANÁ. 1985. Mapeamento dos municípios do Estado do Paraná. Curitiba, PR. 341p.

SOUZA, A.G. SOARES FILHO, C.V., MELLA, S.C. 1996. Espécies forrageiras recomendadas para o Paraná. In: MONTEIRO, A.L.G., MORAES, A., CORRÊA, E.A.S. et al. (Eds.). Forragicultura no Paraná. Londrina: CPAF. p.196-205.

VIANA, O.J., CARNEIRO, M.S.S., REGO, M.C. et al. Estudo de diferentes alturas de corte em capim elefante (Pennisetum purpureum Shum.) In: REUNIÃO ANUAL DA SOCIEDADE BRASILEIRA DE ZOOTECNIA, 30, 1993, Rio de Janeiro. Anais... Rio de Janeiro: SBZ, 1993. p.114.

WARMKE, H.E. 1951. Cytotaxonomic investigation of some varieties of Panicum maximum and $P$. purpurascens in Puerto Rico. Agron. J., 43(1):143-191.

Recebido em: 06/10/97

Aceito em: 16/03/00 